\title{
Copyright Legislation and Library Photocopying
}

\section{Jack Weigel}

Physics-Astronomy Library, The University of Michigan

For the second time in recent years the United States Senate has approved a bill (Senate Bill 22) which would completely revise U.S. copyright law. If the House of Representatives passes a bill containing the same photocopying provisions as Senate Bill 22, the consequences for library users of serials throughout North America could be disastrous.

Although the proposed legislation explicitly grants the right of "fair use" copying, this right is promptly cancelled by Section $108 \mathrm{~g}$ of the bill, where "systematic" photocopying is banned. There is absolutely no consensus among librarians and publishers about the meaning of the word "systematic" in this context. Some publishers have argued that "systematic" copying means any copying by any part of a library system; this includes public library systems, university library systems, library networks, and all libraries with holdings shown in union lists of serials. The broadness of the publishers' interpretation is supported by the commentary of the Senate Judiciary Committee in Senate Report 94--473:

"Multiple copies and systematic reproduction"

Subsection (g) provides that the rights granted by this section extend only to the "isolated and unrelated reproduction of a single copy," but this section does not authorize the related or concerted reproduction of multiple copies of the same material whether made on one occasion or over a period of time, and whether intended for aggregate use by one individual or for separate use by the individual members of a group. For example, if a college professor instructs his class to read an article from a copyrighted journal, the school library would not be permitted, under subsection (g), to reproduce copies of the article for members of the class.

Subsection (g) likewise prohibits the systematic reproduction or distribution of 1) copies (or phonorecords) or articles or other contributions to copyrighted collections or periodicals, or 2) small parts of other copyrighted works. This prohibition holds whether or not multiple copies are reproduced or distributed. Systematic reproduction or distribution occurs when a library makes copies of materials available to other libraries or to groups of users under formal or informal arrangements whose purpose or effect is to have the reproducing library serve as their source of such material. Such systematic reproduction and distribution, as distinguished from isolated and unrelated reproduction or distribution, may substitute the copies reproduced by the source library for subscriptions or reprints or other copies which the receiving libraries or users might otherwise have purchased for themselves, from the publisher or the licensed reproducing agencies.

While it is not possible to formulate specific definitions of "systematic copying," the following examples serve to illustrate some of the copying prohibited by subsection (g).

(1) A library with a collection of journals 
in biology informs other libraries with similar collections that it will maintain and build its own collection and will make copies of articles from these journals available to them and their patrons on request. Accordingly, the other libraries discontinue or refrain from purchasing subscriptions to these journals and fulfill their patrons' requests for articles by obtaining photocopies from the source library.

(2) A research center employing a number of scientists and technicians subscribes to one or two copies of needed periodicals. By reproducing photocopies of articles the center is able to make the material in these periodicals available to its staff in the same manner which otherwise would have required multiple subscriptions.

(3) Several branches of a library system agree that one branch will subscribe to particular journals in lieu of each branch purchasing its own subscriptions, and the one subscribing branch will reproduce copies of articles from the publication for users of the other branches.

If this is indeed the meaning of a ban on "systematic" copying, then the current interlibrary loan arrangements for serials use are clearly endangered. Because of the heavy penalties imposed by the proposed law (up to $\$ 50,000$ for a single violation), most large research libraries will feel compelled to halt all photocopying for external users. Furthermore, copying within a given institution may have to be restricted or rearranged. Libraries which belong to profit-making companies are singled out in the bill for a special prohibition on copying for their own employees.

There have been lengthy negotiations within joint committees of librarians and publishers in an effort to work out a system for collecting royalty payments without generating excessive bookkeeping expenses; no such system has been established. Furthermore, most publishers are not prepared to sell reprints of serial articles or to grant copying permission promptly and at a reasonable cost.

Apparently, the publishers suppose that a cutoff of photocopying will lead to an appreciable increase in library subscriptions for serials, but anyone familiar with the state of library acquisitions budgets will know that this is not so. Since the publishing industry shows at the moment little interest in cooperating with librarians to preserve our existing national system for information exchange via interlibrary loans, networks, etc., the best choice open to the library community now is to fight for alteration or defeat of the proposed copyright law revision. If you agree that "fair use" photocopying is a vital and valid means of information dissemination, then you should write promptly to your local U.S. Representative to urge deletion of the ban on systematic copying or, failing that, rejection of the entire copyright bill.

\section{Library periodicals which you cannot aflord to be without \\ subscribe now!}

Sample copies

and publications lists sent on request

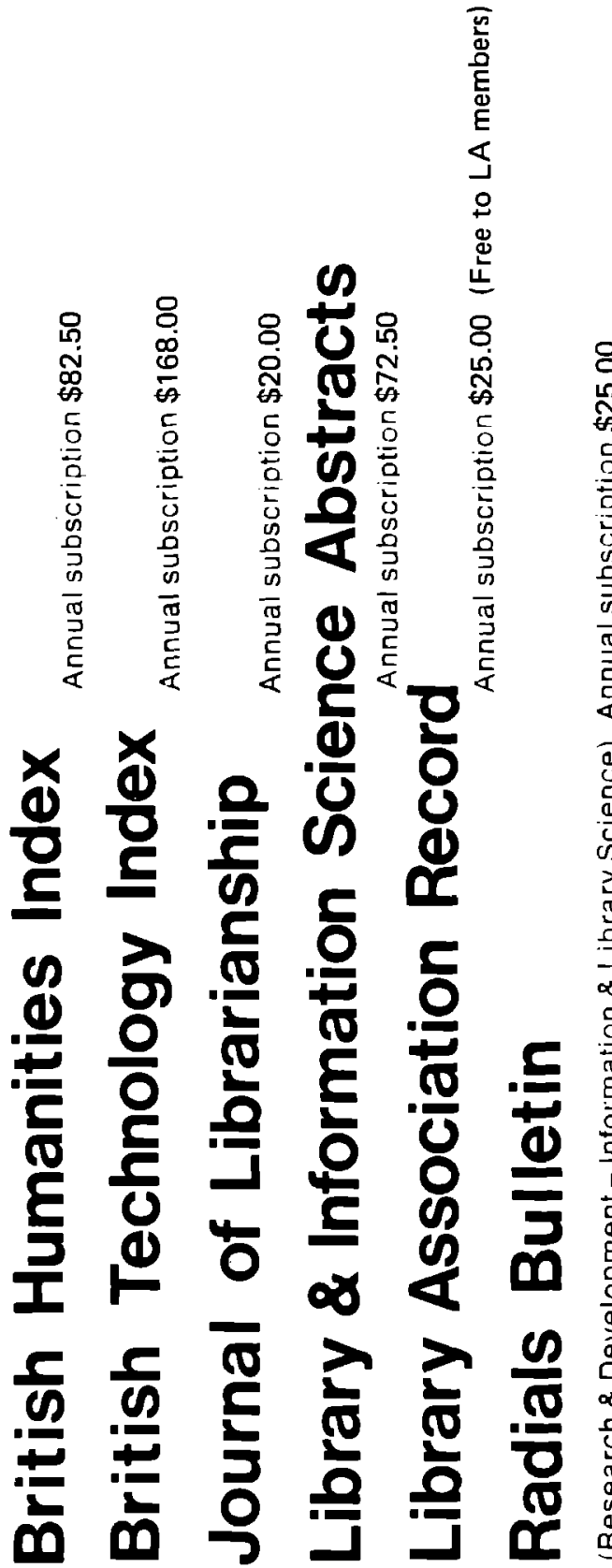

The Library Association

7 Ridgmount Street

London WC1E 7AE England 